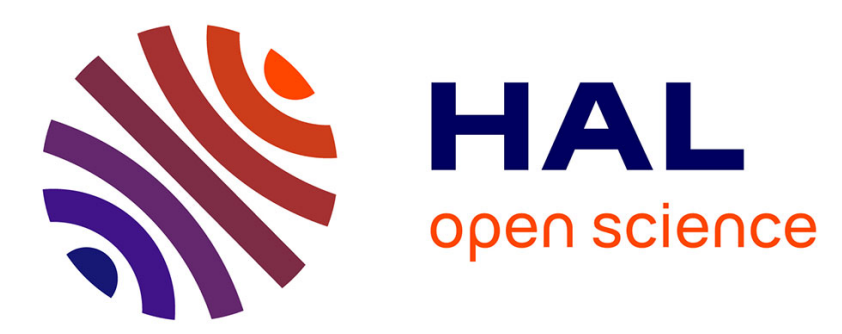

\title{
Sequential order of the binding communication paradigm: A road safety case study
}

Damien Tamisier, Isabelle Ragot-Court, Chloé Eyssartier, Fabien Girandola

\section{To cite this version:}

Damien Tamisier, Isabelle Ragot-Court, Chloé Eyssartier, Fabien Girandola. Sequential order of the binding communication paradigm: A road safety case study. Canadian Journal of Behavioural Science - Revue canadienne des sciences du comportement, 2019, 52, pp48-56. 10.1037/cbs0000162 . hal-02489896

\section{HAL Id: hal-02489896 https://hal.science/hal-02489896}

Submitted on 24 Feb 2020

HAL is a multi-disciplinary open access archive for the deposit and dissemination of scientific research documents, whether they are published or not. The documents may come from teaching and research institutions in France or abroad, or from public or private research centers.
L'archive ouverte pluridisciplinaire HAL, est destinée au dépôt et à la diffusion de documents scientifiques de niveau recherche, publiés ou non, émanant des établissements d'enseignement et de recherche français ou étrangers, des laboratoires publics ou privés. 


\section{Canadian Journal of Behavioural Science / Revue canadienne des sciences du comportement}

\section{Sequential order of the binding communication paradigm: a road safety case study \\ --Manuscript Draft--}

Manuscript Number:

Full Title:

Abstract:

\section{CBS-2019-0846R2}

Sequential order of the binding communication paradigm: a road safety case study

The paradigm of binding communication combines knowledge taken from persuasive communication and the theory of commitment. Conceptually, the paradigm entails performing a low-stakes act and exposure to a persuasive message. In doing so, the likelihood of achieving an effect on behavior is much greater than for strategies solely based on one or the other of these components. However, there is no consensus on the best sequentiality of the binding communication paradigm: traditional usage suggests that the act must be preparatory (meaning prior to the message) while others follow different sequences (during or after the message). The goal of this study is to reveal whether a sequentiality of the paradigm should be preferred to induce motorized two-wheeler drivers (TWD) to reduce their speed. It also aims to confirm the greater efficacy of the binding communication paradigm over commitment or persuasion alone. Results show that TWD placed in the traditional binding communication condition express the greatest intention to reduce their speed and to do so on a larger scale in terms of $\mathrm{km} / \mathrm{h}$. In addition, binding communication confirms in a general manner that a combined approach is more effective than either persuasive communication or a pledged commitment alone.

\section{Article Type:}

Article / Article anonyme

Keywords:

Corresponding Author:

Damien Tamisier

Aix-Marseille Universite

FRANCE

Corresponding Author E-Mail:

damien.tamisier@gmail.com

Corresponding Author Secondary

Information:

Corresponding Author's Institution:

Aix-Marseille Universite

Other Authors:

Isabelle Ragot-Court

Chloé Eyssartier

Fabien Girandola

Corresponding Author's Secondary Institution:

First Author:

Damien Tamisier

Order of Authors Secondary Information:

Manuscript Region of Origin:

FRANCE

\section{Suggested Reviewers:}

\section{Alain Somat}

Universite de Rennes 2

alain.somat@univ-rennes2.fr

Professor of Social Psychology, Specialist in Social Engineering and Applied

Psychology

Isabelle Milhabet

Universite de Nice Sophia Antipolis

milhabet@unice.fr

Professor of Social Psychology, specialist in prevention and binding communication issues

Nicolas Guéguen 
Universite de Bretagne-Sud

nicolas.gueguen@univ-ubs.fr

Professor of social psychology, expert in influence technique and free-will compliance

Opposed Reviewers:

Order of Authors:

Damien Tamisier

Isabelle Ragot-Court

Chloé Eyssartier

Fabien Girandola 
Response to Editor and reviewers

Dear Professor Drapeau,

First of all, we would like to take this opportunity to thank you for the time you have devoted to reviewing and evaluating our work. Thank you for your interest in this study.

We hope that this revised version will meet your expectations and those of the reviewers and that it will meet the requirements of the CJPS with the aim of publishing it in the near future. For your information, here are the changes we have made, in accordance with your recommendations:

- The manuscript was reedited and sent to a professional translation service for language correction and proofreading. Correction marks were made in tracking mode to be easily identifiable. We have decided to show only the new contributions in revision mode and removed all deletion marks to make the document more readable. All the language elements you underlined and many others have been corrected (e.g. "Unfortunately, they have shown..., p. 3, deletion of the word "therefore" appearing too often, concordance of times, etc.).

- The modifications pointed out by the experts are the subject of the next development in response to their comments.

We remain at your disposal for any further modifications or clarifications.

Best regards,

Dear reviewers,

First of all, we would like to thank you for having considered this research with interest. Thank you for the time you have devoted to its review and evaluation. Your comments have improved the quality of the manuscript. We are responding to your comments in the rest of this letter and we hope that the changes made will meet your expectations. 


\section{SEQUENTIAL ORDER OF THE BINDING COMMUNICATION}

The approach of this study follows the study by Tamisier et al. (2019) published in the REPA, whose objective was to explore the effectiveness of protocols likely to optimize binding communication, which is a relatively simple paradigm to implement for road safety fieldworkers. Its objective is to adopt safer behavior and the use of binding communication seems to us to be entirely relevant insofar as the conditions are meant to be interpreted according to the persuasion and commitment paradigms from which the binding communication originates.

Some persuasion techniques such as role-playing (Janis and King, 1954) can have an impact on a counter-attitudinal position (e.g. Greenwald, 1969; Greenwald \& Albert, 1968; Lehman, 1970; Mittler \& Brouch, 1975). Similarly, some commitment techniques also achieve this goal (Pascual, Guéguen, Pujos, and Félonneau, 2013; Guéguen and Pascual, 2015). On the other hand, your comment does indeed challenge us on an alternative - or, rather, complementary — interpretation, but which does not seem to us to be incompatible or to call into questions our argumentation regarding the explanatory processes at stake in the protocol put in place. All things considered, there is nothing to suggest (or refute the suggestion) that the first request (i.e., a request to participate in the development of a campaign) does not put the participant in a situation of dissonance (Joule and Beauvois, 1996). This state of dissonance could indeed be amplified by the second request for the production of arguments and thus echo the work of Lefeuvre and Joule (2002; Joule and Lefeuvre, 2003).

On further reflection, the same could be true for the interpretation of previous results found in the study by Pascual et al. (2013) using commitment theory to anchor their theoretical framework. It could also be assumed that the dissonance of the 1st petition could have been increased by the production of arguments for oneself or reduced when they are directed for others in the work of Tamisier et al. (2019). However, the fact remains that this 
task of producing arguments is irrefutably a binding preparatory act required by the theory of commitment, regardless of any articulation with another theory.

Thus, without questioning the operational interest of experimentation and its anchoring in the paradigms of persuasion (from which counter-attitudinal advocacy is derived) and commitment, it is from a fundamental point of view in the study of the processes involved when a request is counter-attitudinal to question the level of discomfort/induced dissonance and its subsequent effects in seeking rationalization: alternatively or complementary to an induced engagement.

This interpretative approach constitutes a fundamental research perspective and a major challenge that should be explored in depth as part of a separate study. It would therefore be a question of studying a new paradigmatic articulation around persuasion and dissonance which, in our protocol, could be tested by shifting the stage from what we consider to be a preparatory act after the target request (therefore intervening as a second opportunity for rationalization). The measurement of behavioral intentions directly after the first request for participation in the setting up of a new campaign should be the first indicator of rationalization in action following the potential dissonance state. A measure of psychological discomfort could also be injected at different times in the protocol in order to accurately determine the level of discomfort induced at each step.

For all these reasons, we consider it necessary to address this avenue under discussion rather than in the theoretical framework in order not to overwhelm the objectives of this study and suggest these innovative avenues as a perspective. With your agreement, we would therefore like to include your reflection in the discussion.

We are sure that you will understand and would like to thank you more broadly for this rich and promising discussion.

We remain at your disposal for any further modifications or clarifications.

Best regards, 
SEQUENTIAL ORDER OF THE BINDING COMMUNICATION 


\title{
Sequential order of the binding communication paradigm and a road safety case
}

\author{
study \\ Damien Tamisier \\ Aix-Marseille Université \\ Isabelle Ragot-Court \\ IFSTTAR \\ Chloé Eyssartier \\ Cerema \\ Fabien Girandola \\ Aix-Marseille Université
}

\begin{abstract}
Author note
Damien Tamisier, Laboratoire de Psychologie Sociale (LPS - EA 849), Aix-Marseille Université ; Isabelle Ragot-Court, isabelle.ragot-court@ifsttar.fr, IFSTTAR (Institut Français des Sciences et Technologies des Transports, de l'Aménagement et des Réseaux), Département Transport, Santé, Sécurité (TS2), Laboratoire Mécanismes d'Accidents (LMA), 304 Chemin Croix Blanche, 13300 Salon-de-Provence.; Chloé Eyssartier, Groupe Sécurité des Déplacements (GSD), Cerema ; Fabien Girandola, Laboratoire de Psychologie Sociale (LPS - EA 849), Aix-Marseille Université.

This manuscript is based on data from Damien Tamisier's doctoral thesis. The authors acknowledge and underline the partnership between the three institutions involved: IFSTTAR, Cerema and Aix-Marseille University.

Correspondence concerning this article should be addressed to Damien Tamisier, Laboratoire de Psychologie sociale, Aix-Marseille Université, 29 Avenue Robert Schuman, 13100 Aix-en-Provence, France.
\end{abstract}

E-Mail : damien.tamisier@gmail.com 
This manuscript was submitted on Friday, January 25, 2019 


\title{
Sequential order of the binding communication paradigm: a road safety case study
}

\author{
Manuscript submitted on Friday, January 25, 2019
}

\begin{abstract}
The binding communication paradigm combines knowledge taken from persuasion and commitment theories. Conceptually, the paradigm entails performing a low-stakes act and exposure to a persuasive message. In doing so, the likelihood of achieving an effect on behavior is much greater than for strategies solely based on one or the other of these components. However, there is no consensus on the best presentation order in the binding communication paradigm: traditional usage suggests that the act must be preparatory (meaning prior to the message) while others follow different sequences (during or after the message). The goal of this study is to examine what presentation sequence is most effective in inducing motorized two-wheeler drivers (TWD) to reduce their speed. It also aims to confirm the greater efficacy of the binding communication paradigm over commitment or persuasion alone. Results show that TWD exposed to the traditional binding communication condition express the greatest intention to reduce their speed and do so to a greater extent in terms of $\mathrm{km} / \mathrm{h}$. In addition, our results confirm in a general manner that a combined approach is more effective than either persuasive communication or a pledged commitment alone.
\end{abstract}

Keywords: Binding communication, sequential order, persuasion, road safety.

\section{Public significance statements}

This study provides road safety stakeholders with information on design and implementation of more effective road safety campaigns. Binding communication increases the likelihood of achieving behavioral change by engaging targets in the process. 


\section{Sequential order of the binding communication paradigm: a road safety case study}

\section{Introduction}

The principles of classic communication are based on the Lasswell model (1948) and involve three essential elements: a source sending a specific message to a target audience. To design a persuasive message, we must therefore ask ourselves the following questions: who says what to whom, through which channel and with which effects? Communications spread by mass media traditionally use persuasion. According to Petty and Cacioppo (2018, p. 5), persuasive communication refers to "any attempt to change beliefs and attitudes as a result of exposure to a communication". The assumption of persuasion researchers is the idea that social attitudes guide behavior (Brown \& Albarracín, 2005; Petty \& Cacioppo, 2018). Historically, even early definitions of social psychology relied on the study of attitudes to better understand the emergence, modification or reinforcement of behavior (Thomas \& Znaniecki, 1918).

Commitment theory, as originally conceptualized by Kiesler (1971), conceptualizes behavioral change as occurring through the use of binding procedures. Research suggests that it is possible to influence behavior in a more sustainable and efficient way through binding commitment (Girandola \& Roussiau, 2003). Some researchers have proposed an innovative paradigm combining persuasive communication and binding procedures (e.g. Girandola, 2003; Girandola \& Joule, 2012). Binding communication produces greater attitudinal and behavioral effects than persuasion or commitment alone. This study therefore aims to confirm the greater effectiveness of this paradigm in order to improve prevention campaigns.

\section{Speed and TWD: statistics and societal challenges}

The modal share of two-wheeler drivers (TWD) in roadway accidents is striking: while they represent only $2 \%$ of the traffic, they account for more than $20 \%$ of the fatal accident statistics (ONISR, 2017). Over an equivalent travel distance, TWD have a 25 times higher risk of deadly accidents than other road users (Phan et al., 2010). Among the factors 
regularly cited in the literature, speed plays a predominant role, both in terms of the incidence of accidents (Aarts \& Van Schagen, 2006; Blackman \& Haworth, 2013; Haglund \& Aberg, 2000; Vlahogianni, Karlaftis, \& Orfanou, 2012) and the severity of injuries (Campbell \& Stradling, 2003; Lin, Chang, Pai, \& Keyl, 2003; Stradling, 2000; Taylor, Lynam, \& Baruya, 2000). Driving speed is usually treated unequivocally, but some research points to the importance of distinguishing speeding violations (i.e. exceeding the legal speed limit) and inappropriate speeding (i.e. excessive speed in a given situation, without necessarily exceeding the speed limit). In fact, the latter type of speeding is generally more severe and recurrent than the former (e.g. ACEM, 2004; Haque, Chin, \& Debnath, 2012; Lardelli-Claret et al., 2005; Taylor et al., 2000; Van Elslande, Fournier, \& Jaffard, 2011). Reducing the absolute speed of TWD in all circumstances therefore constitutes a fundamental road safety objective.

\section{Committing persuasion or persuasive commitment: the importance of the target's status}

The majority of prevention campaigns effectively continue to rely on persuasive communication in an attempt to influence attitudes as a means of achieving changes in behavior (Albarracín, Durantini, \& Earl, 2006). Unfortunately, their behavioral consequences in terms of road safety and speed reduction are remarkably limited. For example, the GADGET project (Guarding Automobile Drivers through Guidance Education and Technologies) showed that persuasive communication fails to significantly reduce accident numbers when it is not employed in combination with another method (Delhomme et al., 1999). Moreover, the strength of the relationship between attitudes and behavior has been questioned for a long time (LaPiere, 1934), and regularly in various meta-analyses (e.g. Ajzen \& Fishbein, 2000; Glasman \& Albarracín, 2006; Wicker, 1969). Girandola and Joule (2012, p. 119) therefore specify that "information and argumentation are thus necessary but not sufficient." 
To increase the likelihood of behavioral change, free-will compliance strategies can also have a great impact. These techniques based on commitment theory (Kiesler, 1971) have participants engage in an action and strengthen the existing bond between participants and their actions (Joule \& Beauvois, 1998). Dupré (2009) even argued that compliance strategies are more effective tactics for influencing behavior than persuasive strategies. Similarly, certain techniques borrowed from the field of persuasive communication, such as the selfpersuasive task of generating arguments, have been empirically shown to have binding potential (Michelik, 2011; Zbinden, 2011), including on this specific topic and population (Tamisier, Ragot-Court, Eyssartier, \& Girandola, in press). This specific task invites participants to produce persuasive arguments themselves. It should be noted that primacy of action is one of the most important principles of commitment (Joule \& Beauvois, 2001). In the field of road safety, Delhomme, Kreel, and Ragot (2008) showed that binding procedures increase the likelihood that drivers will better comply with speed limits even six months after the investigational phase. However, Meineri and Guéguen (2014) have demonstrated that it is not enough to merely make individuals take action during a commitment process. Rather, it is necessary to involve the participants in a preparatory act capable of actually resonating with them. Their study reveals that the way in which the completion of a questionnaire is described will have a considerable impact in terms of commitment. According to Vallacher and Wegner (1987, p. 3), “any action can be identified in many ways, ranging from low-level identities that specify how the action is performed to high-level identities that signify why or with what effect the action is performed". Describing the completion as a way of actively committing and fighting for a cause (high-level identification) is much more compelling than considering it simply a way of expressing an opinion (low-level identification) or not answering any preliminary questionnaire (no action). This concept of action identification is thus a key component of commitment as Joule and Beauvois (1998, p. 69) specify: "externally prompted causes are antithetical to commitment," since they preclude the internalization process for the 
behavior, whereas, conversely, internally prompted causes promote commitment. A nuanced distinction between active participant (performing actions that are not necessarily highly identified) and actor (performing highly identified actions) seems to be fundamental, since this distinction would implicitly make a difference in the level of commitment. Consequently, it seems important to clarify and define passive persuasion as the result of a single exposure to a persuasive message and active persuasion as that exposure accompanied by a weakly or insignificantly identified act. By extension, it is thus possible to distinguish passive or active persuasive communication from another type of communication when it involves an actual and committed stakeholder.

\section{Binding communication and sequentiality of the paradigm}

Binding communication makes it possible to optimize the effects of the procedure on changes in attitudes and/or behavior. According to Courbet, Fourquet-Courbet, Bernard, and Joule (2013, p. 7), the paradigm consists of getting individuals to "carry out, just before, during and/or just after the processing of persuasive information, inexpensive psychomotor 'mini-acts' related to the social and promoted action promoted'. In view of our previous development, we can refine this definition by specifying that these mini-acts must exhibit high-level identification. On one hand, typical prevention campaigns rely on broadcasting the persuasive message first because their implementations are much more convenient from an ecological and methodological point of view when it comes to applied research. As an example, Bourg (2011, study 5) followed an environmental awareness campaign within a large company with a preparatory act (completing a quiz and signing a commitment statement). Employees complied more in the binding communication condition (i.e. message followed by preparatory act) than in the persuasion-alone condition. On the other hand, Girandola and Joule (2012, p. 121) suggest that "the principle of binding communication consists precisely in pre-delivering a persuasive message before carrying out a preparatory 
$a c t "$. Here, binding communication implies that individuals will be brought to complete one or more actions prior being exposed to a persuasive message. From the standpoint of process and theory, this more traditional sequential order makes it possible to increase the likelihood of central processing of the information contained in the message (Demarque, Apostolidis, \& Joule, 2013), but only when the topic is proattitudinal (Michelik, Girandola, Joule, Zbinden, \& Souchet, 2012, p. 233). Considering that speed reduction is counterattitudinal for TWD (Tamisier, 2017), it is unclear whether the same would hold true in this context. According to the prevailing view, the traditional order should optimize the level of compliance among individuals. Conversely, inverting the order of the protocol (i.e., exposure to a persuasive message followed by the completion of a preparatory action) would supposedly only lead to peripheral processing of the message, thereby hindering the commitment process.

However, a comparison of the impact of these two orders has not been made in previous research. The present research directly compares the impact of the two different presentation orders: traditional binding communication (preparatory act then message) and inverted binding communication paradigms (message then committing act). No studies have ever evaluate the impact of employing two different sequential orders to the paradigm within a single investigational protocol for determining the optimal order capable of achieving the highest submission rate.

Although binding communication for road safety purposes is particularly relevant, its application is surprisingly rare, if not absent. However, its effects have already been demonstrated in the fields of environmentalism (Joule,\& Halimi-Falkowicz, 2008; Zbind

In summary, the purpose of this study is to compare various influence strategies, including binding communication (traditional and inverted), persuasive communication (active and passive), and commitment alone.

\section{Hypotheses}


Given that the complying act is binding and that traditional binding communication generates a stronger commitment than persuasive communication or commitment alone on the other hand, we expect that:

\section{Hypothesis 1}

Participants in the binding communication conditions (traditional and inverted) will express a stronger intention to reduce their speed and intend to do so by a greater amount in terms of $\mathrm{km} / \mathrm{h}$ than participants in other conditions (active persuasion, passive persuasion and commitment alone).

\section{Hypothesis 2}

Participants in the traditional binding communication condition will express a stronger intention to reduce their speed and to do so by a greater amount in terms of $\mathrm{km} / \mathrm{h}$ compared to participants placed in the inverted binding communication condition.

\section{Method}

\section{Participants}

Participants were 136 TWD ranging in age from 16 to 67 years (117 men, 19 women; $M_{\mathrm{age}}=37.3, S D=14.4$ ), all randomly recruited during an annual biker event ("Madone des Motards" in Porcaro, France) or in the parking lots of stores and motorcycle dealers near the "Village Moto" in Nantes (France). Most of the participants were male (86\%, n = 117 and $14 \%$ women, $\mathrm{n}=19$ ). After briefly introducing himself, the experimenter asked the bikers if they would agree to participate in an online survey on TWD practices. The majority agreed to give their email address. Only fully completed questionnaires and participants who accepted the binding act were kept.

\section{Procedure}

All participants were randomly assigned to each group. An email with a link to the questionnaire hosted on Limesurvey was sent to all participants. Participants were randomly 
assigned to one of five conditions (traditional binding communication, inverted binding communication, active persuasive communication, passive persuasive communication and commitment alone). We decided that including a control condition would have unnecessarily complicated the design.

The prevention message used in the four conditions other than the commitment alone condition consisted of an image displayed in the center of the screen. The image showed two motorcyclists, one of whom has apparently suffered an accident and is in a wheelchair, waving at one another. A short text preceded the image:

"Road safety stakeholders have developed an awareness campaign intended to convince drivers of two-wheeled motor vehicles to reduce their speed. Thanks for carefully watching the following campaign."

\section{Figure 1 here}

Participants in the passive communication condition were directly exposed to the image and message.

Those in the active communication condition had to respond, in addition to this, to a cognitive response task. This condition satisfies two objectives. First, it confirms the absence of a difference between the active and passive persuasive communication, thus distinguishing them from binding communication requiring a high-level identification act. Second, it provides the opportunity to study the level of information processing in each condition involved. A cognitive response task was thus incorporated among the rest of the conditions alongside exposure to the message (with the exception of the passive persuasive communication).

Participants in the inverted binding communication condition were first exposed to the persuasive message. Then, they read the following introduction to the self-persuasion task:

"The purpose of this research study is to help road safety stakeholders to develop a new campaign intended to convince drivers of two-wheeled motor vehicles to reduce their 


\section{SEQUENTIAL ORDER OF THE BINDING COMMUNICATION}

speed. The effectiveness of this campaign relies on the involvement of two-wheeled vehicle motorists themselves. To this end, we are requesting your participation in helping to design a new message to be used as part of the next upcoming prevention campaign." The binding act was then presented as follows, highlighting their freedom of choice regarding participation to improve commitment (Joule \& Beauvois, 2001; Kiesler, 1971) :

"Would you be willing to give some arguments in favor of reducing your driving speed on motorcycles? Of course, you are free to accept or decline."

Participants in the traditional binding communication procedure had to perform the preparatory act first before being exposed to the message.

Participants in the commitment alone condition were only required to complete the preparatory act, without being exposed to the message.

\section{Measures}

Webb and Sheeran showed that intentions are a good predictor of future behavior. In addition, the correlation between intention to speed and speeding behavior is also strong (Elliot, 2001; Vogel \& Rothengatter, 1984). Thus, behavioral intention to reduce driving speed was assessed. We used a Likert scale ranging on one end from "no intention to slow down whatsoever" (-5) to "full intention to slow down" $(+5)$ on the other. Intention to reduce speed was assessed separately for four types of roadways (city street, beltway, highway and freeway). The purpose of asking about speed reduction intentions in different contexts was to create a more reliable overall intention index and to analyze in detail the results for each road if there were no overall effect.

A further item measured the amount they would agree to reduce their speed by in $\mathrm{km} / \mathrm{h}$ :

- $\quad$ From 1 to $3 \mathrm{~km} / \mathrm{h}$

- $\quad$ From 4 to $7 \mathrm{~km} / \mathrm{h}$

- From 8 to $10 \mathrm{~km} / \mathrm{h}$ 
- From 11 to $15 \mathrm{~km} / \mathrm{h}$

- $\quad$ More than $15 \mathrm{~km} / \mathrm{h}$;

- Confirm that they have no intention to reduce their speed.

For exploratory purposes, participants were asked to list all thoughts that came to mind when they looked at the picture. The cognitive response task was only provided for the binding communication conditions and the active persuasive communication condition.

\section{Results}

\section{Intention and behavioral amplitude of speed reduction}

In accordance with the recommendations of Brauer and McClelland (2005), preference was given to contrasts for processing data because our hypotheses are particularly specific. Equality of variances was not found for intention using Levene's test $(p=.218)$ or behavioral amplitude $(p=.956)$. The overall means for each experimental condition are reported in Table 1.

\section{Table 1 here}

The contrast $\mathrm{C} 1(-2,-2,-2,+3,+3)$ corresponds to the conditions of passive persuasion, active persuasion, commitment alone, inverted binding communication, and traditional binding communication, respectively. $\mathrm{C} 1$ tests the difference between the two binding communication conditions and all of the other conditions taken as a single group. In order to meet the conditions set by Brauer and McClelland (2005), we have systematically added three other contrasts that are allegedly not significant with respect to the independent variable, C2 $(0,+1,-2,0,+1), \mathrm{C} 3(-1,0,0,+2,-1)$ and $\mathrm{C} 4(-1,+2,-1,0,0)$. Indeed, they recommend creating $m$-1 contrasts, where $m$ represents the total number of investigational conditions. These three final contrasts are, respectively, not significant, with $\mathrm{C} 2$ : $\mathrm{F}(1,130)=$ 1.26, ns; $\mathrm{C} 3: \mathrm{F}(1,130)=-.263, n s$ and $\mathrm{C} 4: \mathrm{F}(1,130)=.039$, ns. Insofar as none of these three contrasts will become significant at any later time, they will not be mentioned any further. 
For our first hypothesis, C1 reveals a significant difference for behavioral intention, $\mathrm{F}(1,130)=11.72, p=.001, r_{\mathrm{C} 1}=.282^{1}$. This means that participants in the binding communication conditions $(M=-0.31, S D=2.32)$ have a stronger intention to reduce their speed than participants in the other experimental groups taken as a single group $(M=-1.03$, $S D=2.5)$. On the other hand, $\mathrm{C} 1$ is not significant for size of behavior change, $\mathrm{F}(1,130)=-$ $1.38, n s$.

The contrast D1 $(-1,-1,-1,-1,+4)$ tests the difference between the traditional binding communication condition and the group of all other conditions taken together. D1 reveals a significant difference for behavioral intention, $\mathrm{F}(1,130)=17.14, p=.000, r_{\mathrm{D} 1}=.341$, signifying that those in the traditional binding communication condition $(M=.43, S D=2.06)$ have a greater intention of reducing their speed than the participants from all of the other conditions taken as a single group $(M=-1.61, S D=2.52)$.

D1 additionally reveals a significant difference in size, $\mathrm{F}(1,130)=4.94, p=.037, r_{\mathrm{D} 1}$ $=.19$, indicating that the traditional binding communication condition participants $(M=1.99$, $S D=1.28$ ) have the intention of reducing their speed to a greater extent (in $\mathrm{km} / \mathrm{h}$ ) than the rest of the sample $(M=1.36, S D=1.24)$.

The contrast E1 $(0,0,0,-1,+1)$ isolates and tests specifically our second hypothesis, that participants in the traditional binding communication condition would express a stronger intention to reduce their speed and to do so by a greater amount in terms of $\mathrm{km} / \mathrm{h}$ than participants in the inverted binding communication condition. E1 reveals a significant difference for behavioral intention, $\mathrm{F}(1,130)=4.64, p=.037, r_{\mathrm{E} 1}=.172$. This means that the participants in the traditional binding communication condition $(M=.43, S D=2.06)$ have a greater intention to reduce their speed than the participants in the inverted binding communication condition $(M=-1.04, S D=2.57)$. 
E1 additionally reveals a trend toward a difference in size, $\mathrm{F}(1,130)=3.05 p=.083$, $r_{\mathrm{E} 1}=.149$, suggesting that participants in the binding communication condition $(M=1.99, S D$ $=1.28$ ) reduced their speed to a greater extent in $\mathrm{km} / \mathrm{h}$ than those in the inverted binding communication condition $(M=1.35, S D=1.19)$.

The contrast $F 1(-1,-1,+2,0,0)$ tests the difference between the two conditions involving persuasion and commitment alone separately. F1 does not reveal any difference in intention, $\mathrm{F}(1,130)=.92$, ns, or for size, $\mathrm{F}(1,130)=.54$, ns. This means that the participants in the persuasive conditions do not have a greater intention to reduce their speed than the participants in the commitment alone condition, nor do they intend to reduce speed by a greater amount.

The contrast $\mathrm{G} 1(-1,+1,0,0,0)$ tests the difference between the two persuasive conditions taken separately. G1 does not reveal any difference in intention, $\mathrm{F}(1,130)=.42$, $n s$, or in size, $\mathrm{F}(1,130)=.30, n s$. Thus, participants in the active persuasion and passive persuasion conditions did not differ in their intention to speed or the amount they intended to reduce their speed by.

\section{Cognitive responses}

No differences were reported among the conditions in terms of quantity and valence of the arguments, which signifies that information processing is equal among all groups.

\section{Discussion}

This study aimed to test and confirm the relevance of the binding communication paradigm by comparing it with different influence strategies in the field of road safety. Planned contrast analyses revealed that participants in the binding communication condition as a whole (traditional and inverted) have a greater intention to reduce their speed compared to participants who are subject to persuasive communication (active or passive) and commitment only. 
A second objective was to determine whether the sequence in which the binding communication and the persuasive communication were presented was important. Even though the cognitive response task has not made it possible to confirm use of the central route in information processing, the traditional binding communication condition significantly differed from the inverted binding communication condition, not only with regard to behavioral intention but also with regard to amount of behavior change in relation to absolute speed. This former group is also the only one expressing a positive behavioral intention. In other words, motorcyclists who performed a preparatory act before being exposed to a persuasive message had a greater intention to reduce their speed and planned to reduce it more than the other participants. These results are consistent with Girandola and Joule's (2012) definition emphasizing the importance of an act that is not only committing but also preparatory (i.e. before processing persuasive information). Nevertheless, future research would benefit from testing the hypothesis of central processing by focusing on a pro-social, normative or desirable request. Indeed, speed remains a sensitive issue for TWD, especially since it is one of the main factors that motivate their driving practices and is part of their motorcyclist identity (Elliott, 2010; Van Elslande, 2009). In addition, TWD drivers have a positive attitude towards speed (Tamisier, 2017), and the classic effects associated with selective exposure theory stipulate that an individual will seek to avoid information that is inconsistent with his attitude. Thus, the probability that participants will use the peripheral route of information processing remains high, especially because a strong attitude influences information processing and is more resistant to persuasion (Krosnick \& Petty, 1995).

As a follow-up to this idea, we also wonder not only whether the effect obtained in this study depends on the committing nature of the preparatory act, but also whether it can be interpreted in terms of the theory of cognitive dissonance (Festinger, 1957) by assuming that the acceptance of a first problematic request (to agree to take part in an action in a communication campaign which advocates a limitation of speed) would impact participants 
differently depending on the conditions. In a traditional binding communication environment, the preparatory act would constitute a second cognition that increases dissonance (Joule \& Lefeuvre, 2003; Lefeuvre \& Joule, 2002) and, consequently, the willingness to reduce it by adopting a stronger behavioral intention. Conversely, only accepting exposure to counterattitudinal information would not sufficiently increase this discomfort and would result in a weaker behavioral intention. Although this study does not allow for a clear decision on those questions, future investigations would be worthwhile considering, for example, involving other criteria such as the degree of perceived involvement, perceived psychological discomfort or an implicit measurement of attitude.

This research also challenges the conclusions of Dupré (2009) by showing that solely commitment-based strategies are not systematically better than persuasion only. It appears to be dependent on the population and topic under study, especially with regard to a counterattitudinal act. The relevance of persuasion and, more broadly, the complementary nature of the binding communication paradigm remains, as its implementation improves the efficiency of a communication campaign.

Moreover, a comparison of the two persuasion conditions (active and passive) backs up the conclusions drawn by Meineri and Guéguen (2014), lending support to the idea that a preparatory act is not binding by nature and needs to be highly identified (Vallacher \& Wegner, 1987). Even though the cognitive-response task entails reflection on the part of the participant, this is based on nothing more than the examination of a passively received message. It is thus not enough to involve an individual in the simple completion of a task regardless of its nature. The binding communication condition here incorporates the participant in a progressive and high-stakes self-influencing process that promotes the internalization of behaviors ("I am what I do"). Joule and Beauvois (2001) suggest that an internalized act will be much more binding than an act issued under duress or driven by an extrinsic motivation. Girandola and Joule (2012, p. 121) therefore insist on the crucial 
importance of considering two new questions to distinguish traditional communication from binding communication: "what is the appropriate level of action identification, and especially what preparatory act must be obtained from the target". In this regard, Laurens and Moscovici (2005) have claimed that, by assigning a dual status to the individual as both the source and the target, self-persuasion is no longer oriented toward a single stimulus (a mere response to the researcher's request) but instead toward a more significant goal (convincing both oneself and someone else with notional and induced obligation to attain results). This task underlines their identity as $2 \mathrm{WD}$ drivers, to which they particularly attach importance (Banet \& Bellet, 2009; Del Sarto, 2012). By encouraging drivers to focus on themselves, it also leads to better effects when the request is counterattitudinal. Briñol McCaslin and Petty (2012) point out that the individual is more focused on finding the most relevant arguments, which we believe would have a direct impact on their commitment level. Registering an additional layer of responsibility, implicit in this preparatory act, therefore makes it possible to enhance the effects of compliance (Guéguen, 2002). Among the limitations of this study, the absence of a control group does not allow us to have a standard measure of drivers' behavioral intention. Also, this group would have allowed us to probably reveal more significant effects and to compare the separate effects of persuasion and commitment.

Then, a measure of effective or, at least, self-reported behaviors in a longitudinal approach would have allowed us to broaden the scope of our results which remain, given the predictability of behaviors by intentions (Webb \& Sheeran, 2006) and the high correlation between speed intention and behavior (Elliot, 2001; Vogel \& Rothengatter, 1984), particularly instructive. Even though in vivo assessment of effective driver speeds would likely be limited by technical and financial constraints, the subjective nature of self-declared behaviors could possibly constitute an initial index suitable for assessing behavioral changes.

This result therefore reinforces the existing literature and extends support for the effectiveness of binding communication to the field of road safety. Although further research 
is needed, this study provides important information to public road safety stakeholders with the means to design and evaluate new campaigns on specific target. Binding communication seems promising in addressing road safety issues as long as the targets are first committed in a relevant preparatory act.

\section{Declaration of interest statement}

The authors have no competing interests.

\section{Acknowledgments}

We'd like to thank the French Road Safety Delegation for allowing us to freely use the image of the "remain a biker on your bike" campaign in this study.

\section{References}

Aarts, L., \& Van Schagen, I. (2006). Driving speed and the risk of road crashes: A review. Accident Analysis \& Prevention, 38(2), 215-224. https://doi.org/10.1016/j.aap.2005.07.004

ACEM. (2004). In-depth investigation of accidents involving powered two-wheelers. Final report 1.2. Brussels: Association of European Motorcycle Manufacturers (ACEM).

Ajzen, I., \& Fishbein, M. (2000). Attitudes and the attitude-behavior relation: Reasoned and automatic processes. European Review of Social Psychology, 11(1), 1-33. https://doi.org/10.1080/14792779943000116

Albarracín, D., Durantini, M. R., \& Earl, A. (2006). Empirical and theoretical conclusions of an analysis of outcomes of HIV-prevention interventions. Current Directions in Psychological Science, 15(2), 73-78.

Banet, \& Bellet. (2009). Attitudes face aux risques et à la prise de risque: Étude comparative chez différentes populations de motocyclistes. Les Deux-Roues Motorisés: Nouvelles Connaissances et Besoins de Recherche, 191-217.

Blackman, \& Haworth, N. (2013). Comparison of moped, scooter and motorcycle 
crash risk and crash severity. Accident Analysis \& Prevention, 57, 1-9.

Bourg, G. (2011). L'apport de la communication engageante et des représentations sociales dans le cadre de la promotion de l'éco-mobilité ( $\mathrm{PhD}$ Thesis). Université de Bourgogne.

Brauer, M., \& McClelland, G. (2005). L'utilisation des contrastes dans l'analyse des données: Comment tester les hypothèses spécifiques dans la recherche en psychologie? L’année Psychologique, 105(2), 273-305.

Briñol, P., McCaslin, M. J., \& Petty, R. E. (2012). Self-generated persuasion: Effects of the target and direction of arguments. Journal of Personality and Social Psychology, 102(5), 925-940.

Brown, R. D., \& Albarracín, D. (2005). Attitudes over time: Attitude judgment and change. Understanding Behavior in the Context of Time: Theory, Research, and Applications, $187-204$.

Campbell, M., \& Stradling, S. G. (2003). Factors influencing driver speed choices.

Courbet, D., Fourquet-Courbet, M.-P., Bernard, F., \& Joule, R.-V. (2013). Communication persuasive et communication engageante pour la santé Favoriser des comportements sains avec les médias, Internet et les serious games. In press.

Del Sarto, M. (2012, December 21). Approche psychosociale de la sécurité routière: Représentations sociales, Risque et Prévention. Le cas des Motards.

Delhomme, P., Kreel, V., \& Ragot, I. (2008). The effect of the commitment to observe speed limits during rehabilitation training courses for traffic regulation offenders in France. Revue Européenne de Psychologie Appliquée/European Review of Applied Psychology, 58(1), $31-42$.

Delhomme, P., Vaa, T., Meyer, T., Goldenbeld, C., Jaermark, S., Christie, N., \& Rehnova, V. (1999). Deliverable 4: Evaluated road safety media campaigns : an overview of 265 evaluated campaigns and some meta-analysis on accidents. GADGET Project Contract 
No RO-97-SC. 2235.

Demarque, C., Apostolidis, T., \& Joule, R.-V. (2013). Consideration of future consequences and pro-environmental decision making in the context of persuasion and binding commitment. Journal of Environmental Psychology, 36, 214-220.

Dupré, M. (2009). De l'engagement comportemental à la participation: Élaboration de stratégies de communication sur le tri et la prévention des déchets ménagers (Thèse de doctorat). Université Rennes 2; Université européenne de Bretagne.

Elliot, B. (2001). The application of the Theorists' Workshop Model of Behaviour Change to motorists' speeding behaviour in Western Australia (unpublished report). Western Australia: Office of road safety, Department of Transport.

Elliott, M. A. (2010). Effects of theory of planned behaviour, identity and social identity constructs on motorcyclists intentions to speed. Injury Prevention, 16(Supplement 1), A9-A10. https://doi.org/10.1136/ip.2010.029215.33

Festinger, L. (1957). A theory of cognitive dissonance. Stanford University Press.

Girandola, F. (2003). Psychologie de la persuasion et de l'engagement (Vol. 4). Presses Univ. Franche-Comté.

Girandola, F., \& Joule, R.-V. (2012). La communication engageante: Aspects théoriques, résultats et perspectives. L'année Psychologique, 112(1), 115-143.

Girandola, F., \& Roussiau. (2003). L'engagement comme source de modifications à long terme. Cahiers Internationaux de Psychologie Sociale, 57(1), 83-101.

Glasman, L. R., \& Albarracín, D. (2006). Forming attitudes that predict future behavior: A meta-analysis of the attitude-behavior relation. Psychological Bulletin, 132(5), 778-822. https://doi.org/10.1037/0033-2909.132.5.778

Guéguen, N. (2002). Psychologie de la soumission et de la manipulation. Dunod, Paris.

Haglund, M., \& Aberg, L. (2000). Speed choice in relation to speed limit and 
influences from other drivers. Transportation Research Part F: Traffic Psychology and Behaviour, 3(1), 39-51.

Haque, M. M., Chin, H. C., \& Debnath, A. K. (2012). An investigation on multivehicle motorcycle crashes using log-linear models. Safety Science, 50(2), 352-362.

Joule, R.-V., \& Beauvois, J.-L. (1998). La soumission librement consentie: Comment amener les gens à faire librement ce qu'ils doivent faire? Presses universitaires de France.

Joule, R.-V., \& Beauvois, J.-L. (2001). La théorie de l'engagement. La Psychologie Sociale, 5, 25-35.

Joule, R.-V., Bernard, F., \& Halimi-Falkowicz, S. (2008). Promoting ecocitizenship: In favor of binding communication. International Scientific Journal for Alternative Energy and Ecology, 6(62), 214-218.

Joule, R.-V., \& Lefeuvre, R. (2003). Contrat expérimental et réduction de la dissonance cognitive dans le paradigme de la double soumission: Une nouvelle perspective de recherche. Nouvelle Revue de Psychologie Sociale, 2, 87-96.

Kiesler, C. A. (1971). The psychology of commitment: Experiments linking behavior to belief. Academic Press New York.

Krosnick, J. A., \& Petty, R. E. (1995). Attitude strength: An overview. Attitude Strength: Antecedents and Consequences, 1, 1-24.

LaPiere, R. T. (1934). Attitudes vs. Actions. Social Forces, 13(2), 230-237.

Lardelli-Claret, P., Jimenez-Moleon, J. J., de Dios Luna-del-Castillo, J., GarciaMartin, M., Bueno-Cavanillas, A., \& Galvez-Vargas, R. (2005). Driver dependent factors and the risk of causing a collision for two wheeled motor vehicles. Injury Prevention, 11(4), 225231.

Lasswell, H. D. (1948). The structure and function of communication in society. The Communication of Ideas, 37, 215-228.

Laurens, S., \& Moscovici, S. (2005). The confederate's and others' self-conversion: A 
SEQUENTIAL ORDER OF THE BINDING COMMUNICATION

neglected phenomenon. The Journal of Social Psychology, 145(2), 191-208. https://doi.org/10.3200/socp.145.2.191-208

Lefeuvre, R., \& Joule, R. V. (2002). Effets cognitifs du type de contrat expérimental dans une situation de double soumission: Double contrat et contrat global. Les Cahiers Internationaux de Psychologie Sociale, 56, 47-56.

Lin, M.-R., Chang, S.-H., Pai, L., \& Keyl, P. M. (2003). A longitudinal study of risk factors for motorcycle crashes among junior college students in Taiwan. Accident Analysis \& Prevention, 35(2), 243-252.

Meineri, S., \& Guéguen, N. (2014). Foot-in-the-door and action identification. Binding communication applied to environmental conservation. Revue Européenne de Psychologie Appliquée/European Review of Applied Psychology, 64(1), 3-11. https://doi.org/10.1016/j.erap.2011.12.003

Michelik, F. (2011). La communication engageante: Effets sur les dimensions cognitives et comportementales. Besançon.

Michelik, F., Girandola, F., Joule, R.-V., Zbinden, A., \& Souchet, L. (2012). Effects of the Binding Communication Paradigm on Attitudes. Swiss Journal of Psychology, 71(4), 227235.

ONISR. (2017). Bilan de la sécurité routière sur les données d'accidentologie 2016. Retrieved from http://www.securite-routiere.gouv.fr/medias/espace-presse/publicationspresse/bilan-definitif-de-l-accidentalite-routiere-2017

Petty, R. E., \& Cacioppo, J. T. (2018). Attitudes and persuasion: Classic and contemporary approaches. Routledge.

Phan, V., Regan, M., Moutreuil, M., Minton, R., Mattsson, M., \& Leden, L. (2010). Using the driving reliability and error analysis method (DREAM) to understand powered twowheeler accident causation. Int. Conf. on Safety and Mobility of Vulnerable Road Users: Pedestrians, Motorcyclists and Bicyclists, Jerusalem. 
Rosnow, R. L., Rosenthal, R., \& Rubin, D. B. (2000). Contrasts and Correlations in Effect-Size Estimation. Psychological Science, 11(6), 446-453. https://doi.org/10.1111/14679280.00287

Stradling, S. (2000). Drivers who speed. Impact, 9(2).

Tamisier, D. (2017). La communication engageante au service d'une problématique de sécurité routière: La réduction de la vitesse des conducteurs de deux-roues motorisés (Thèse de doctorat). Aix-Marseille Université.

Tamisier, D., Ragot-Court, I., Eyssartier, C., \& Girandola, F. (in press). Binding communication and problematic request: Application in the field of road safety.

Taylor, Lynam, \& Baruya. (2000). The effects of drivers' speed on the frequency of road accidents. Transport Research Laboratory Crowthorne.

Thomas, W. I., \& Znaniecki, F. (1918). The Polish peasant in Europe and America: Monograph of an immigrant group (Vol. 2). University of Chicago Press.

Vallacher, R. R., \& Wegner, D. M. (1987). What do people think they're doing? Action identification and human behavior. Psychological Review, 94(1), 3.

Van Elslande, Fournier, J. Y., \& Jaffard, M. (2011). Facteurs d'accidents, défaillances fonctionnelles et configurations accidentelles. I. Ragot-Court et P. Van Elslande,(Eds.), Les Comportements et Leurs Déterminants Dans l'accidentalité Des Deux-Roues Motorisés (COMPAR), Volet, 1.

Van Elslande, P. (2009). Les deux-roues motorisés: Nouvelles connaissances et besoins de recherche. Les Collections de l'Inrets, Bron.

Vlahogianni, E. I., Karlaftis, M. G., \& Orfanou, F. P. (2012). Modeling the effects of weather and traffic on the risk of secondary incidents. Journal of Intelligent Transportation Systems, 16(3), 109-117.

Vogel, R., \& Rothengatter, J. A. (1984). Motives for speeding behavior on highways: An attitudinal study. Report VSC, 84-09. 
Webb, T. L., \& Sheeran, P. (2006). Does changing behavioral intentions engender behavior change? A meta-analysis of the experimental evidence. Psychological Bulletin, 132(2), 249.

Wicker, A. W. (1969). Attitudes versus Actions: The Relationship of Verbal and Overt Behavioral Responses to Attitude Objects. Journal of Social Issues, 25(4), 41-78. https://doi.org/10.1111/j.1540-4560.1969.tb00619.x

Zbinden, A. (2011). Communication engageante et représentations sociales: Une nouvelle articulation théorique (Thèse de doctorat). Université de Bourgogne.

Zbinden, Souchet, Girandola, F., \& Bourg. (2011). Communication engageante et représentations sociales: Une application en faveur de la protection de l'environnement et du recyclage. Pratiques Psychologiques, 17(3), 285-299. 
Tables

Table 1 Mean values for behavioral intention and size of behavior change for reducing driving speed

\begin{tabular}{lccc}
\hline Condition & $n$ & \multicolumn{1}{c}{$M_{\text {intention }}(S D)$} & $M_{\text {size }}(S D)$ \\
\hline Passive persuasion & 35 & $-2.2(2.42)$ & $1.2(1.24)$ \\
Active persuasion & 32 & $-1.78(2.83)$ & $1.36(1.21)$ \\
Commitment alone & 22 & $-1.41(2.26)$ & $1.51(1.32)$ \\
Inverted binding communication & 23 & $-1.04(2.57)$ & $1.35(1.19)$ \\
Traditional binding communication & 23 & $.43(2.06)$ & $1.99(1.28)$ \\
\hline $\begin{array}{l}\text { Note. A higher mean value for intention signifies that participants do have an actual intent to } \\
\text { reduce their driving speed. A higher mean value for size signifies that participants have an }\end{array}$ \\
actual intent to reduce their driving speed to a greater extent in terms of km/h.
\end{tabular}

Figures 


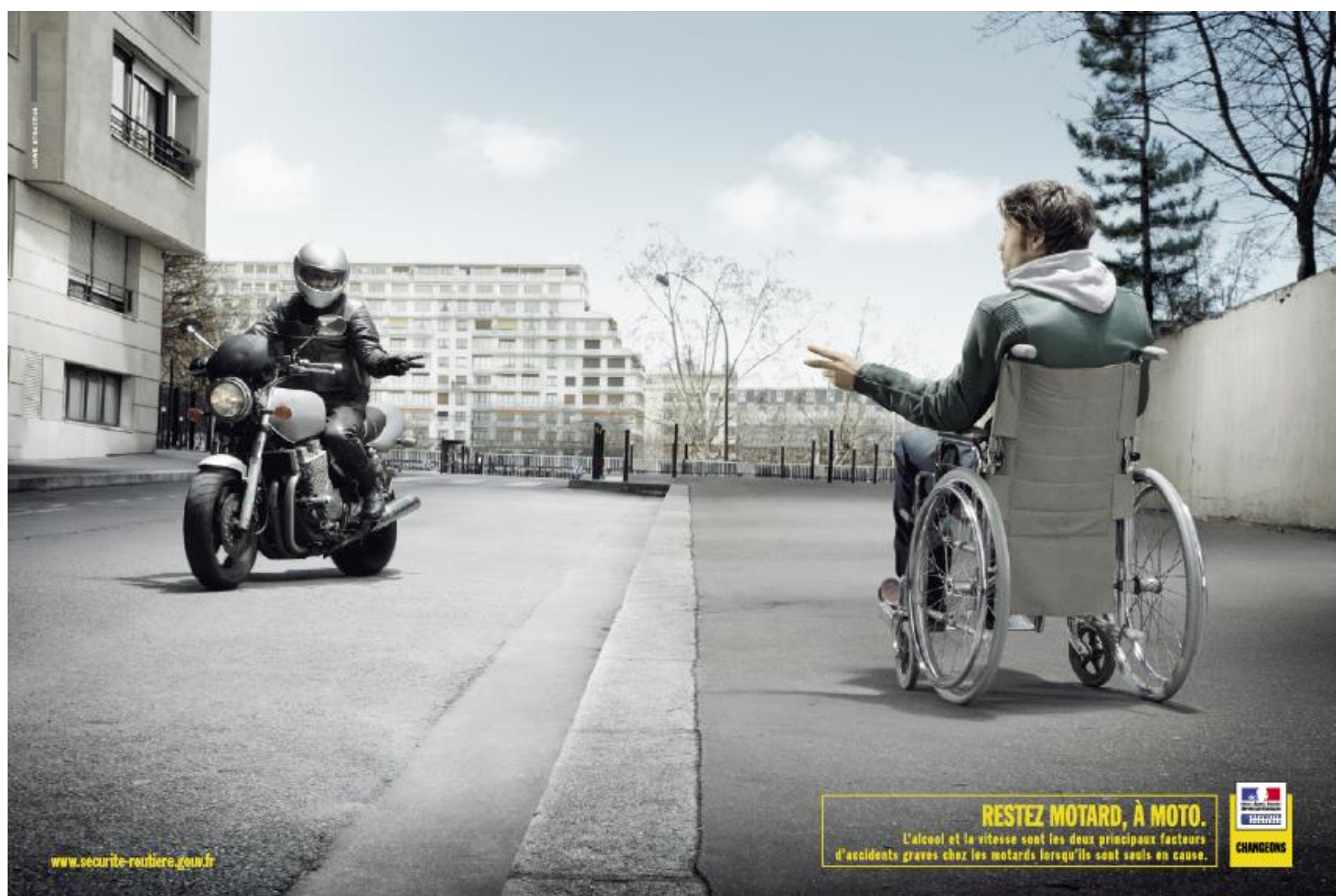

Figure 1 Persuasive message taken from the "Restez motard, à moto [Remain a biker, on your bike]" campaign 
Table 1 Mean values for behavioral intention and amplitude for reducing driving speed

\begin{tabular}{cccc}
\hline Condition & $\mathrm{n}$ & $\mathrm{M}_{\text {intention }}(\mathrm{SD})$ & $\mathrm{M}_{\text {breadth }}(\mathrm{SD})$ \\
\hline Passive persuasion & 35 & $-2.2(2.42)$ & $1.2(1.24)$ \\
Active persuasion & 32 & $-1.78(2.83)$ & $1.36(1.21)$ \\
Commitment alone & 22 & $-1.41(2.26)$ & $1.51(1.32)$ \\
Inverted binding communication & 23 & $-1.04(2.57)$ & $1.35(1.19)$ \\
Traditional binding communication & 23 & $.43(2.06)$ & $1.99(1.28)$
\end{tabular}

Note. A higher mean value for intention signifies that participants do have an actual intent to reduce their driving speed. A higher mean value for breadth signifies that participants have an actual intent to reduce their driving speed to a greater extent in terms of $\mathrm{km} / \mathrm{h}$. 


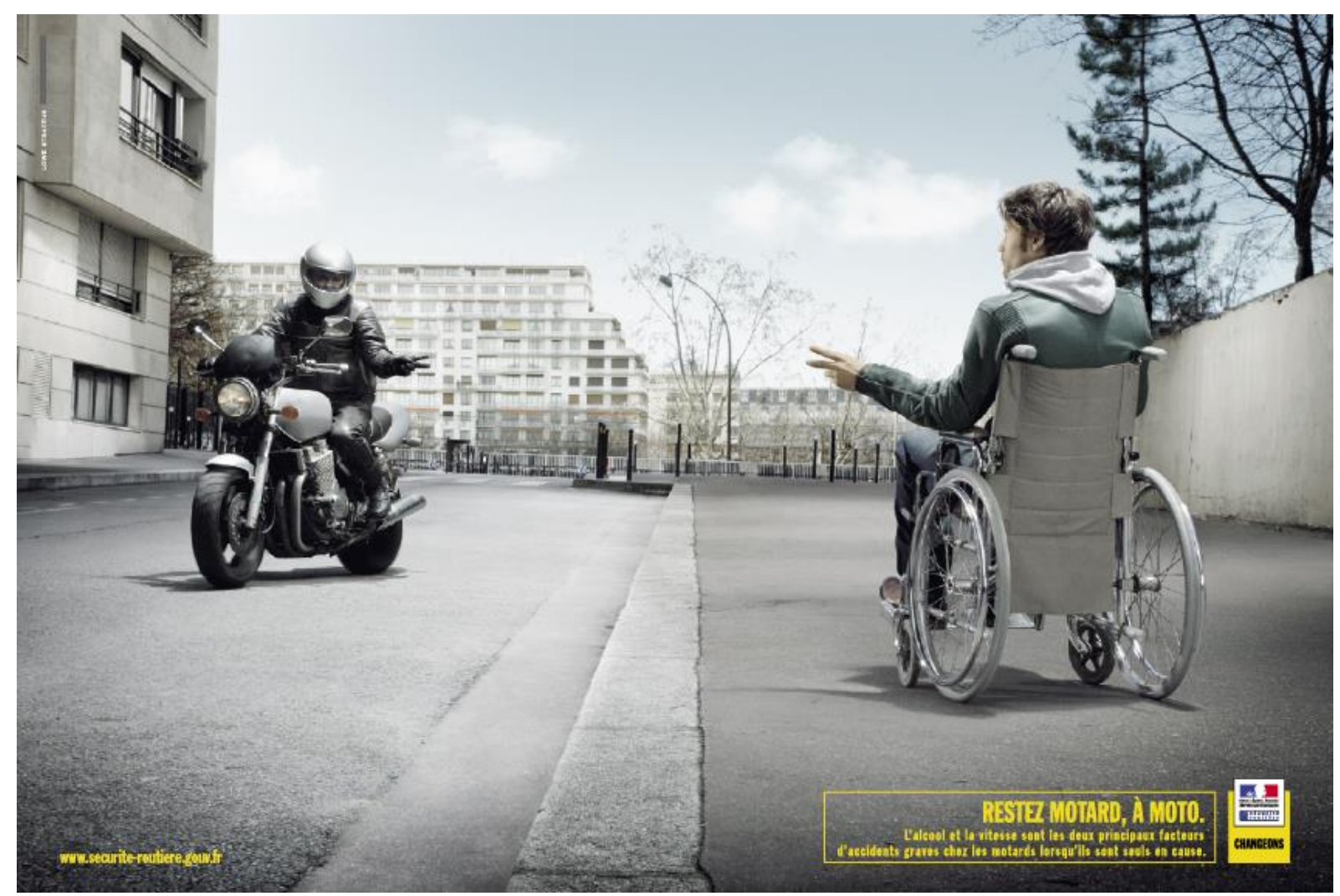

Figure 1 Persuasive message taken from the campaign "Remain a biker, on your bike" 